\title{
Occurrence and molecular characterization of Cryptosporidium in dogs in Henan Province, China
}

\author{
Fuchun Jian ${ }^{1,2}$, Meng Qi ${ }^{1,2}$, Xiaoyi He ${ }^{3}$, Rongjun Wang ${ }^{1,2}$, Sumei Zhang ${ }^{1,2}$, Heping Dong ${ }^{1}$ and Longxian Zhang ${ }^{1,2^{*}}$
}

\begin{abstract}
Background: Cryptosporidiosis in dogs has been reported worldwide, involving both asymptomatic and diarrheic dogs. Large-scale surveys of Cryptosporidium infection in dogs have been performed in some countries using differents diagnostic methods. But, few data are available on the infection rate and molecular characteristics of Cryptosporidium spp. in dogs in China.

Result: In this study, 770 fecal samples from 66 locations in Henan Province were examined. The average Cryptosporidium infection rate was $3.8 \%$, with dogs in kennels having the highest rate of $7.0 \%\left(X^{2}=14.82, P<0.01\right)$. The infection rate was $8.0 \%$ in dogs younger than 90 days, which was significantly higher than that in the other age groups $\left(1.1-3.8 \% ; X^{2}=18.82, P<0.01\right)$. No association was noted between the infection rate and the sex of the dogs. Twenty-nine Cryptosporidium-positive samples were amplified at the small subunit rRNA (SSU rRNA), 70-kDa heat shock protein (HSP70), and actin loci using PCR. Sequence analysis of these amplicons identified only Cryptosporidium canis, which showed 100\% identity with the published sequences of the SSU rRNA, HSP70, and actin genes.

Conclusions: Our results confirm that C. canis is popular in the dog population in China, considering the large number of dogs in China and the close contact between dogs and humans, the role of $C$. canis in the transmission of human cryptosporidiosis warrants attention.
\end{abstract}

Keywords: Infection rate, Dogs, Cryptosporidium canis, SSU rRNA, HSP70, Actin

\section{Background}

Cryptosporidium spp. are important zoonotic protozoan parasites that infect more than 280 species of vertebrate animals and can cause acute or chronic diarrhea and even death [1]. So far, at least 26 valid Cryptosporidium species have been named, and more than 73 hostadapted genotypes of undetermined species status have been described [1,2].

Dogs are often considered to be faithful friends and intimate companions of humans. However, dogs and cats also act as reservoirs for a large number of pathogens of parasitic zoonoses, including cryptosporidiosis. Cryptosporidium canis, the most frequently identified species of Cryptosporidium in dogs, has been found in stray and

\footnotetext{
* Correspondence: zhanglx8999@gmail.com

${ }^{1}$ College of Animal Science and Veterinary Medicine, Henan Agricultural University, Zhengzhou 450002, P R, China

${ }^{2}$ International Joint Research Laboratory for Zoonotic Diseases of Henan, Zhengzhou 450002, P R, China

Full list of author information is available at the end of the article
}

domesticated dogs worldwide [3-10], although small numbers of zoonotic C. parvum, C. muris, and C. meleagridis have also been detected in dogs [7,11-16]. Cryptosporidium canis is considered a potentially zoonotic Cryptosporidium species based on its presence in human patients in the United Kingdom, Jamaica, Kenya, Peru, Thailand, and the United States $[1,17,18]$.

In China, the history of raising dogs goes back more than 6000 years [19]. The total number of dogs in China at present is vast, with the number of pet dogs alone approaching 200 million [20]. This large number of dogs may be a serious threat to public health because of the widespread occurrence of rabies and other zoonotic diseases, including cryptosporidiosis. Unfortunately, only a few studies of cryptosporidiosis in dogs in China have been reported, all of which were published in the Chinese language and none of which included genotype analyses [21-23]. Therefore, in this study, we used molecular methods to identify the Cryptosporidium species present in a relatively 
extensive survey of dogs and evaluated the risk of zoonotic infections.

\section{Results and discussion}

The overall infection rate with Cryptosporidium was $3.8 \%(29 / 770)$. This is similar to the rates in studies conducted in the United States (2.0 and 3.8\%) and Italy $(3.3 \%)$, and one survey in China (2.59\%) [6,28,29], whereas the infection rate was slightly lower than those reported in Japan (3.9\%), Iran (5\%), and Canada (9.3\%) $[9,10,14]$. No clinical signs were apparent in any of the Cryptosporidium-positive dogs at the time of specimen collection. The infection rates of Cryptosporidium spp. in dogs in kennels, pet shops, pet hospitals, and the police canine center were $7.0 \%(16 / 229 ; 95 \%$ CI: $7.0 \pm$ $0.23 \%), 4.5 \%$ (11/246; $95 \%$ CI: $4.5 \pm 0.17 \%), 1.0 \%$ (2/206; $95 \%$ CI: $1.0 \pm 0.09 \%)$, and 0 (0/89), respectively (Table 1$)$. These differences might be partly attributable to the various feeding and management practices used and to hygienic conditions. For example, in the police canine center, each dog was kept in a single shed and the feces excreted by the dogs were cleared in a timely manner by the dogs' handlers, whereas the dogs in kennels were kept together, which increased the chance of crosstransmission among them.

The Cryptosporidium infection rates differed with age. The highest infection rate was $8.0 \%$ (95\% CI: $8.0 \pm$ $0.06 \%$ ) and was found among dogs aged $<90$ days and the lowest rate of $1.1 \%$ (95\% CI: $1.1 \pm 0.08 \%$ ) was found among dogs aged $>360$ days $\left(\chi^{2}=18.82, \quad P<0.01\right.$; Table 2). The decreasing Cryptosporidium infection rate with increasing age is consistent with several recent studies conducted in Norway and China [28,30,31]. In contrast, no significant relationship was seen between the occurrence of Cryptosporidium and the sex of the dogs: the infection rate was $4.2 \%(15 / 353)$ in female dogs and $3.4 \%(14 / 417)$ in male dogs $\left(\chi^{2}=0.42, P>0.05\right)$. Two studies conducted in China and Brazil reported similar findings $[22,32]$. This indicates that sex is not a major issue affecting Cryptosporidium infection in dogs.

All 29 Cryptosporidium-positive samples were successfully amplified with nested PCR at the SSU rRNA locus.

\begin{tabular}{|c|c|c|c|}
\hline Collection site & No. samples & No. positive & $\begin{array}{l}\text { Prevalence } \\
(95 \% \mathrm{Cl})(\%)\end{array}$ \\
\hline Kennel & 229 & 16 & $7.0 \pm 0.23$ \\
\hline Pet shop & 246 & 11 & $4.5 \pm 0.17$ \\
\hline Pet hospital & 206 & 2 & $1.0 \pm 0.09$ \\
\hline Police canine center & 89 & 0 & 0 \\
\hline Total & 770 & 29 & $3.8 \pm 0.05$ \\
\hline
\end{tabular}

Table 2 Cryptosporidium infection rates among dogs of different ages

\begin{tabular}{llll}
\hline Age & No. samples & No. positive & Prevalence $(\mathbf{9 5 \%} \mathbf{C l}) \mathbf{( \% )}$ \\
\hline$<90$ days & 251 & 20 & $8.0 \pm 0.06$ \\
$90-180$ days & 150 & 4 & $2.7 \pm 0.21$ \\
$181-360$ days & 98 & 2 & $2.0 \pm 0.28$ \\
$>360$ days & 271 & 3 & $1.1 \pm 0.08$ \\
Total & 770 & 29 & $3.8 \pm 0.05$ \\
\hline
\end{tabular}

RFLP analysis of the SSU rRNA gene products revealed that these samples belonged to C. canis. DNA sequencing of the SSU rRNA PCR products from 12 C. canispositive samples confirmed the identity of the species, with $100 \%$ similarity to dog- and human-derived C. canis sequences in GenBank [5]. To further evaluate the molecular characteristics of $C$. canis in this study, two $C$. canis isolates were sequenced at the HSP70 locus and eight at the actin locus. As expected, the two HSP70 sequences were identical to those obtained previously from dog-derived C. canis (AF221529) and coyote-derived C. canis (AY120920). Similarly, the four actin sequences (EU754834-EU754837) were identical to that of a dogderived isolate (AF382340). The other four actin sequences (EU754838-EU754841) were identical to each other, and differed from isolates EU754834-EU754837 and AF382340 by only one nucleotide. Phylogenetic analysis of the SSU rRNA, HSP70, and actin genes confirmed the identity of $C$. canis in this study.

As in this study, C. canis has been identified as the most common Cryptosporidium species in dogs around the world, although a few cases of $C$. parvum, C. muris, and $C$. meleagridis infection have also been reported [1,11,12,14,17,22,30,33-35]. Unlike C. parvum, C. canis appears to have a relatively high level of host adaptability. A few cases of C. canis have also been reported in both immunocompromised and immunocompetent individuals in recent years [15,36-40]. Although a recent study suggested that cryptosporidiosis from pet dogs and cats poses only a minimal zoonotic risk, the possible public-health implications of $C$. canis and the economic significance of C. canis infections in dogs and other animals cannot be ignored [41].

\section{Conclusion}

In the present study, we described the occurrence and molecular characteristics of Cryptosporidium in dogs in China using a large number of samples. This provides useful information that may extend our understanding of the prevalence of Cryptosporidium infections in dogs. China has a large number of dogs, all of whom are in close contact with humans. Therefore, because only $C$. canis was identified in dogs in this study, it is possible 
that $C$. canis is an emerging zoonotic infectious agent in some parts of China.

\section{Methods}

\section{Ethics statement}

Before beginning work on the present study, we contacted animal owners and obtained their permission to include their animals in the study. All animal experiments were conducted in accordance with the Chinese Laboratory Animal Administration Act 1988. Before the experiment, the protocol of the study was reviewed and approved by the Research Ethics Committee of Henan Agricultural University.

\section{Fecal samples and microscopic examination}

Fresh fecal samples were collected from March 2006 to December 2009 from 26 locations in different places in Henan Province, China, including kennels, pet shops, pet hospitals, and a police canine center. A total of 770 samples were used in the study, including those from animals aged $<90,90-180,181-360$, and $>360$ days (Table 2). Fecal samples of at least $25 \mathrm{~g}$ were examined for the presence of Cryptosporidium oocysts using bright-field microscopy of the fecal material that had been concentrated with the formalin-ethyl acetate sedimentation method and Sheather's sugar flotation technique [24]. Cryptosporidium-positive samples were stored in $2.5 \%$ potassium dichromate at $4^{\circ} \mathrm{C}$.

\section{DNA extraction}

The genomic DNA from nine Cryptosporidium-positive samples from kennels, identified between 2006 and 2007, was extracted from the purified oocysts by discontinuous density sucrose gradient centrifugation using a MagExtractor-Genome kit (Toyobo Co., Ltd., Osaka, Japan). The genomic DNA from the remaining 20 Cryptosporidiumpositive samples from kennels, pet shops, and pet hospitals, identified between 2008 and 2009, was isolated using an E. Z.N.A. Stool DNA Kit (OMEGA Biotek Inc., Norcross, GA, USA). DNA samples were stored at $-20^{\circ} \mathrm{C}$ before molecular analysis.

\section{Cryptosporidium genotyping}

The SSU rRNA gene of Cryptosporidium was amplified from microscopy-positive samples using nested PCR, according to previously described procedures, and restriction fragment length polymorphism (RFLP) analysis [25], using the restriction enzymes $S s p \mathrm{I}$ and VspI (Fermentas, Shenzhen, China). Two-directional sequencing of 12 representative samples (two from pet hospitals, four from pet shops, and six from kennels) was performed with an $\mathrm{ABI}$ Prism 3730 DNA Analyzer (Applied Biosystems, Foster City, CA, USA) using the Big Dye Terminator v3.1 Cycle Sequencing Kit (Applied Biosystems). Some of the positive samples were further characterized by sequence analyses of the HSP70 gene (the two from pet shops and another two from kennels) and actin gene (the two from pet hospitals, the two from pet shops, and another four from kennels). The identities based on the gene loci of these samples were similar to those of the sequenced SSU rRNA samples. The primers and procedures used for these two loci were taken from previous studies $[26,27]$. The sequences of the actin genes were analyzed after the genes were cloned into the pGEM1-T Easy vector (Promega, Shanghai, China).

\section{Data analysis}

The sequences were analyzed using ClustalX 1.83 (http:// www.clustal.org/) and Phylip 3.69 (http://cmgm.stanford. edu/phylip/). Representative sequences of the C. canis isolates were deposited in GenBank under accession numbers EU754826-EU754833 (SSU rRNA), EU754834-EU754841 (actin), and EU754842-EU754843 (HSP70). The $\chi^{2}$ test was used to compare the Cryptosporidium infection rates in the different groups of dogs. Differences were considered significant at $P<0.05$.

\section{Competing interests}

The authors declare that they have no competing interests.

\section{Authors' contributions}

LXZ conceived and designed the experiments; FCJ, MQ, and HPD performed the experiments; FCJ and RJW analyzed the data; XYH and CSN contributed reagents/materials/analysis tools; FCJ and LXZ wrote the paper. All authors have read and approved the final version of the manuscript.

\section{Acknowledgments}

This study was supported, in part, by the Key National Science and Technology Specific Projects (no. 2012ZX10004-220), the Program for Innovative Research Team (in Science and Technology) of the University of Henan Province (no. 2012IRTSTHN005), and the International Cooperation and Exchange of the National Natural Science Foundation of China (no. 31110103901)

\section{Author details}

${ }^{1}$ College of Animal Science and Veterinary Medicine, Henan Agricultural University, Zhengzhou 450002, P R, China. International Joint Research Laboratory for Zoonotic Diseases of Henan, Zhengzhou 450002, P R, China. ${ }^{3}$ Xiangya School of Medicine, Central South University, Changsha 410013, $P R$, China.

Received: 7 August 2013 Accepted: 15 January 2014 Published: 17 January 2014

\section{References}

1. Fayer R: Taxonomy and species delimitation in Cryptosporidium. Exp Parasitol 2010, 124(1):90-97.

2. Ren X, Zhao J, Zhang L, Ning C, Jian F, Wang R, Lv C, Wang Q, Arrowood MJ, Xiao L: Cryptosporidium tyzzeri n. sp. (Apicomplexa: Cryptosporidiidae) in domestic mice (Mus musculus). Exp Parasitol 2012, 130(3):274-281.

3. Xiao L, Ryan U: Cryptosporidiosis: an update in molecular epidemiology. Curr Opin Infect Dis 2004, 17(5):483-490.

4. Xiao L, Cama VA, Cabrera L, Ortega Y, Pearson J, Gilman RH: Possible transmission of Cryptosporidium canis between children and a dog in a household. J Clin Microbiol 2007, 45(6):2014-2016.

5. Xiao L, Fayer R: Molecular characterization of species and genotypes of Cryptosporidium and Giardia and assessment of zoonotic transmission. Int J Parasitol 2008, 38(11):1239-1255. 
6. Giangaspero A, lorio R, Paoletti B, Traversa D, Capelli G: Molecular evidence for Cryptosporidium infection in dogs in central Italy. Parasitol Res 2006, 99(3):297-299

7. Philip J, Lupo RC, Langer C, Mary R, Pablo CO, Cynthia LC: Cryptosporidium muris in a Texas Canine Population. Am J Trop Med Hyg 2008, 78(6):917-921

8. Himsworth CG, Skinner S, Chaban B, Jenkins E, Wagner BA, Harms NJ, Leighton FA, Thompson RC, Hill JE: Multiple Zoonotic Pathogens Identified in Canine Feces Collected from a Remote Canadian Indigenous Community. Am J Trop Med Hyg 2010, 83(2):338-341.

9. Beiromvand M, Akhlaghi L, Fattahi Massom SH, Meamar AR, Motevalian A, Oormazdi H, Razmjou E: Prevalence of zoonotic intestinal parasites in domestic and stray dogs in a rural area of Iran. Prev Vet Med 2013, 109(1-2):162-167.

10. Uehlinger FD, Greenwood SJ, McClure JT, Conboy G, O'Handley R, Barkema HW: Zoonotic potential of Giardia duodenalis and Cryptosporidium spp. and prevalence of intestinal parasites in young dogs from different populations on Prince Edward Island, Canada. Vet Parasitol 2013, 196(3-4):509-514.

11. Miller D, Liggett A, Radi Z, Branch L: Gastrointestinal cryptosporidiosis in a puppy. Vet Parasitol 2003, 115(3):199-204.

12. Molloy SF, Smith HV, Kirwan P, Nichols RA, Asaolu SO, Connelly L, Holland CV: Identification of a high diversity of Cryptosporidium species genotypes and subtypes in a pediatric population in Nigeria. Am J Trop Med Hyg 2010, 82(4):608-613.

13. Ellis $A E$, Brown CA, Miller DL: Diagnostic exercise: chronic vomiting in a dog. Vet Pathol 2010, 47(5):991-993.

14. Yoshiuchi R, Matsubayashi M, Kimatal I, Furuya M, Tani H, Sasai K: Survey and molecular characterization of Cryptosporidium and Giardia spp. in owned companion animal, dogs and cats, in Japan. Vet Parasitol 2010, 174(3-4):313-316.

15. Scorza AV, Duncan C, Miles L, Lappin MR: Prevalence of selected zoonotic and vector-borne agents in dogs and cats in Costa Rica. Vet Parasitol 2011, 183(1-2):178-183.

16. Hajdusek $O$, Ditrich $O$, Slapeta J: Molecular identification of Cryptosporidium spp. in animal and human hosts from the Czech Republic. Vet Parasito/ 2004, 122(3):183-192.

17. Gatei W, Barrett D, Lindo JF, Eldemire-Shearer D, Cama V, Xiao L: Unique Cryptosporidium population in HIV-infected persons Jamaica. Emerg Infect Dis 2008, 14(5):841-843.

18. Elwin K, Hadfield SJ, Robinson G, Chalmers RM: The epidemiology of sporadic human infections with unusual cryptosporidia detected during routine typing in England and Wales, 2000-2008. Epidemiol Infect 2012, 140(4):673-683.

19. Li Q: Brief history of Chinese dog-raising (in Chinese). China J Dog raising 1990, 2:27.

20. Chen J, Xu MJ, Zhou DH, Song HQ, Wang CR, Zhu XQ: Canine and feline parasitic zoonoses in China. Parasit Vectors 2012, 5:152.

21. Dong H, Zhang L, Ning C, Wang Y, Yang H, Shi K, Gao G: Epidemiological investigation on cryptosporidiosis in dogs in Zhengzhou and experimental infection with oocysts derived from the dogs (in Chinese). Vet Sci China 2007, 37:854-858.

22. Wang J, Li P, Xue X, Chen X, Jiang S, Qiu X, Yin GL: Investigation on the infection situation of Crypotosporidium in dogs in Hefei city (in Chinese). Chin J Vet Parasitol 2008, 16(5):20-23.

23. Ma L, Wang G, Lu Y, Cai Q, Ye C, Li X, Niu X: ELISA detection of canie cryptosporidiosis in Qinghai province, China (in Chinese). J Vet Parasitol 2010, 18:65-67.

24. McNabb SJ, Hensel DM, Welch DF, Heijbel H, McKee GL, Istre GR: Comparison of sedimentation and flotation techniques for identification of Cryptosporidium sp. oocysts in a large outbreak of human diarrhea. J Clin Microbiol 1985, 22(4):587-589.

25. Xiao L, Morgan UM, Limor J, Escalante A, Arrowood M, Shulaw W, Thompson RC, Fayer R, Lal AA: Genetic diversity within Cryptosporidium parvum and related Cryptosporidium species. Appl Environ Microbol 1999, 65(8):3386-3391.

26. Sulaiman IM, Lal AA, Xiao L: Molecular phylogeny and evolutionary relationships of Cryptosporidium parasites at the actin locus. J Parasitol 2002, 88(2):388-394

27. Sulaiman IM, Morgan UM, Thompson RC, Lal AA, Xiao L: Phylogenetic relationships of Cryptosporidium parasites based on the 70-kilodalton heat shock protein (HSP70) gene. Appl Environ Microbol 2000, 66(6):2385-2391.

28. El-Ahraf A, Tacal JVJ, Sobih M, Amin M, Lawrence W, Wilcke BW: Prevalence of cryptosporidiosis in dogs and human beings in San Bernardino County. California. J Am Vet Med Assoc 1991, 198(4):631-634.

29. Irwin PJ: Companion animal parasitology: a clinical perspective. Int $J$ Parasitol 2002, 32(5):581-593.

30. Hamnes IS, Gjerde BK, Robertson LJ: A longitudinal study on the occurrence of Cryptosporidium and Giardia in dogs during their first year of life. Acta Vet Scand 2007, 49:22-32.

31. Yu L, Li P, Gu Y, Xu W, Wang X, Qiu X, Yin G: Epidemiological survey of dog cryptosporidiosis in Hefei (in Chinese). J Anhui Sci Tech Univ 2009, 23:15-18.

32. Huber F, Bomfim TCB, Gomes RS: Comparison between natural infection by Cryptosporidium sp. Giardia sp. in dogs in two living situations in the West Zone of the municipality of Rio de Janeiro. Vet Parasitol 2005, 130(1-2):69-72.

33. Ederli BB, Rodrigues MF, Carvalho CB: Oocysts of the genus Cryptosporidium in domiciliated dogs from city of Campos dos Goytacazes, the State of Rio de Janeiro. Rev Bras Parasitol Vet 2005 14(3):129-131.

34. Mandarino-Pereira A, de Souza FS, Lopes CW, Pereira MJ: Prevalence of parasites in soil and dog feces according to diagnostic tests. Vet Parasitol 2010, 170(1-2):176-181.

35. Bajer A, Bednarska M, Rodo A: Risk factors and control of intestinal parasite infections in sled dogs in Poland. Vet Parasitol 2011, 175(3-4):343-350.

36. Xiao L, Bern C, Limor J, Sulaiman I, Roberts J, Checkley W, Cabrera L, Gilman $\mathrm{RH}$, Lal AA: Identification of 5 types of Cryptosporidium parasites in children in Lima. Peru. J Infect Dis 2001, 183(3):492-497.

37. Caccio SM: Molecular epidemiology of human cryptosporidiosis. Parassitologia 2005, 47(2):185-192.

38. Gatei W, Suputtamongkol Y, Waywa D, Ashford RW, Bailey JW, Greensill J, Beeching NJ, Hart CA: Zoonotic species of Cryptosporidium are as prevalent as the anthroponotic in HIV infected patients in Thailand. Ann Trop Med Parasitol 2002, 96(8):797-802.

39. Learmonth JJ, lonas G, Ebbett KA, Kwan ES: Genetic characterization and transmission cycles of Cryptosporidium species isolated from humans in New Zealand. Appl Environ Microbiol 2004, 70(7):3973-3978.

40. Leoni F, Amar C, Nichols G, Pedraza-Diaz S, McLauchlin J: Genetic analysis of Cryptosporidium from 2414 humans with diarrhea in England between 1985 and 2000. J Med Microbiol 2006, 55(Pt 6):703-707.

41. Dwight DB, Araceli LF: Cryptosporidiosis and giardiasis in dogs and cats: veterinary and public health importance. Exp Parasitol 2010, 124(1):121-127.

doi:10.1186/1746-6148-10-26

Cite this article as: Jian et al:: Occurrence and molecular characterization of Cryptosporidium in dogs in Henan Province, China. BMC Veterinary Research 2014 10:26

\section{Submit your next manuscript to BioMed Central and take full advantage of:}

- Convenient online submission

- Thorough peer review

- No space constraints or color figure charges

- Immediate publication on acceptance

- Inclusion in PubMed, CAS, Scopus and Google Scholar

- Research which is freely available for redistribution 